\title{
Research and Enlightenment of Japanese Preschool Education based on Picture Books
}

\author{
Lili Dong ${ }^{1, a}$
}

${ }^{1}$ College of Foreign Languages, Jilin Agricultural University, Changchun, Jilin, China, 130118

a email

\section{Keywords: Japanese Preschool Education, Picture Books, Enlightenment}

\begin{abstract}
Since the 20th century, picture book is internationally recognized as the most suitable books for young children to read, because of its beautiful screen, humorous stories and rich in features, and "Platform" which proposed "to guide children in contact with outstanding children's literature, use picture, paintings and a variety of other ways to lead children's interest in books, reading, writing and reading skills". It has attention and favor by the majority of kindergarten teachers, most kindergarten teachers will teach picture book as a daily teaching activity. But in the study, we find that the majority of teachers still have many problems and confusion in the teaching of picture books.
\end{abstract}

\section{Introduction}

The term "picture books" from Japan and Taiwan of China introduced called. Now recognized as the first "picture book" 1903 British writer Beatrix Potter (Beatrix Potter) directed the painting of the "story of Peter Rabbit," a book, this is the first book for children depicting the creation of the picture story book, is considered the beginning of modern children's picture books.

Children's picture books are designed for children. Due to the age and character of the child, how their focus is different from adults. Illustrated creation should be designed for children of different ages in line with the psychological characteristics and ability to understand the story and picture, rich in content, and more involved in literature, science, and education. Picture books designed for children is usually big screen, colorful, full of interesting content, from the mundane life of departure for rich imagination, knowledge, reason and emotion through a screen pass to children. Children's picture book can be a good help parents and teachers in the family and school education of children about knowledge and sharing emotions. Clever graphic design, harmony and proper colors make beautiful images with very high aesthetic value. Through reading and observation, children can get to enjoy unlimited visual aesthetic experience, and subtly enhanced inner joy and happiness. Content of the story contains a lot of content, involving different philosophy of life and unlimited topic.

\section{Japanese Picture Book Culture Education}

If the picture animations can be played continuously moving picture book is then painted on paper still picture. Most people think that there is equal Illustrated picture book which is a generalized concept so there have been many anecdotal form packed with picture books picture books children poems, rhymes picture books, picture books and so on mathematics. Accurate to say, Illustrated Books is an independent form with particular emphasis on the intrinsic relationship between the map and the text is to use pictures and text describes a common form in which the picture story books occupied a very important component. Some picture books or even only picture segment has the same text but there is the story, which is another feature of picture books. Picture book author and film director to be equivalent to those paintings in a limited space to tell the story nicely, paint it to look is a combination of text and drawings skillfully cold people put it down. Therefore, Di Yi explained: picture books is to use a set of pictures to tell stories rely flip to advance the plot, even illiterate people by looking at the picture and guess work out the effect. Although there is no children's picture books animation audio-visual advantage but it can blank the screen, the page 
space beyond imagination, etc., so that even if everyone read the text and illustrations are seeing the same mind in the story but they can have a richer world the change.

Children's picture books are mostly adapted from a story comes in the process of adaptation will inevitably have to cut, modify the original layer to modify the original development of the plot of the story. And we have seen illustrations of different books in general, children's picture books and illustrations in the text are equal relationship can even dominate and pictures as there is a logical relationship between the front and rear of narrative painting and body painting and the text just as drawing aids. Because of the importance of illustrations so it requires a folk tale illustrator painter not only familiar with the text of the story simple text is replaced by the text drawing more to tap the hidden part of the text can not express images using pictures shown .

In the past the elderly Children and adults will listen with their ears legends. Now it is the folk stories through a series of adaptations to select the appropriate content into picture books for children make it into the books continue the cultural heritage. If only the production of picture books editor of the Japanese folk tale filling camel stuffed into picture books for children, then to some extent this is a cultural regression. Mr. Matsui straight in his book pointed out to us a clear way, that is, from picture books for adults on the text read to their children listen to,) L while children enjoy their own eyes illustration. This is because although the language of painting and has a sense of unity, but sometimes fight each other. Read picture books for children to read in their own time when there will be between the text and the gap is difficult to plug both into one. But parents read to when the two are combined will be able to spot the child while listening to the story - living side in the heart of the story to see the world like to see the real picture book world.

\section{Chinese Situation in Kindergarten Picture Books Teaching}

Illustrated teaching Kindergarten teaching activities has now become an integral part of, but in full swing to carry out the kindergarten picture books teaching the same time, there are still many problems, even blind "fashion" suspect "herd". Therefore, this part of the status quo mainly use the questionnaire, interviews, analysis of current events live in kindergarten picture books teaching investigation and analysis, and picture books teaching summarizes the problems, improve research in preparation for later practices.

Illustrated by kindergarten teachers universal acceptance and love, is an indisputable fact, many teachers also have to carry out picture books teaching experience. From the survey results, this paper points out the majority of teachers a reasonable proportion of picture books and graphic relationship, coherence, etc. Understanding between the screen plot are still in place, but in-depth interviews have found that teachers' understanding of picture books is not very clear, especially is the difference in picture books and other types of picture books. In practice, teachers' understanding of picture books still exist slippery concept of mixing phenomena, such as the difference between picture books and picture books in the general sense among teachers usually vague, often "do not know", "not very usual to distinguish" "not much difference" or that "the picture book is a picture book, books," and so to answer. The survey also found that many kindergartens regarded as their own picture books teaching Kindergarten characteristics of teaching, teachers are required to carry out regular weekly teaching a picture book? Twice, but did not organize a teacher of picture books and picture books teaching training, most teachers Illustrated teaching is carried out more letter swallow or only in accordance with the formula specified in kindergarten picture book reference materials to complete the task of teaching, teachers' understanding of picture books and relevant teaching ability and no real increase.

The survey found that teachers' ability to choose picture books are generally not high current is still in kindergarten picture books teaching more prominent issue. Most teachers in the choice of picture books, will start nursery or garden designated teaching reference an existing picture books considered, mainly to see the characters mentioned although many teachers choose picture books do not meet the age characteristics of children, whether interesting or allegorical themes It is profound and other standards, but generally only in picture books teaching demonstration or exhibition open class when participants consider these factors, other times or to the principle of proximity-based. 
From the study based on the activities of those who recorded the live can be seen, there are nine picture books teaching activities in five kindergarten activities using picture books specified reference textbooks, teachers do not need in-depth analysis and reading picture books, teaching reference only minor modifications you can perform, teachers do not have the ability to choose picture books at all. Many teachers mentioned in the interviews conducted Illustrated teaching the most critical and most difficult is also his comparative lack of choice for outstanding picture books, teachers have been aware of their own lack of visibility in this area.

\section{The Enlightenment of Japanese Preschool Education on Chinese}

Japan focus on early childhood practice so that children get emotional experience through the activities, focusing on the significance of sports games for children, emphasizing personality and overall physical and mental development. Since the seventies, with the Japanese economy to take off, gradually into the process of modernization, Japanese educators can clearly understand and to face the negative effects of modern urbanization brings: man and nature increasingly away from the apartment of the living conditions, and so on into the family television, modern lifestyles have adverse effects on children's physical, mental, and therefore proposed environmental education or nature of education, namely in education to be conscious of the negative impact of modernization to make up, create favorable conditions and environment for the development of children, so that children in close contact nature, enjoy the game in nature, active exploration, development and emotional intelligence.

The survey found, and no picture books most teachers prior to conducting in-depth study based on picture books teaching and learning, although it encourages teachers in kindergarten picture book exhibition teaching, but the method is not appropriate, often ignoring the interests of teachers, teaching level and the picture books the level of awareness, the specified materials for teachers, teachers do not recognize the direct picture books, picture books and even understand the opportunities like picture books, in order to complete the task of teaching the teachers can only skim the surface like a picture book to carry out teaching and understanding of picture books is still little knowledge of the state. Picture books and picture books for teachers on teaching issues related to the concept of lack of awareness, a Subsidiary's first organization to expand teacher training to help teachers better understand the difference between picture book and its characteristics, values, and other types of picture books, as well as to know which areas analysis of how good a good picture book.

Teachers' own "picture book" literacy, such as picture books liking, understanding and awareness level will affect the conduct of picture books teaching. The cause of teachers Illustrated choose not start, can not effectively tap Illustrated themes such issues tend to be due to less contact with the teacher's own picture books, picture books of knowledge and understanding is not enough, so the need to improve teachers' picture book "Literacy through a variety of ways .

In carrying out picture books teaching teachers, we must first establish a correct concept of teaching picture books, picture books teaching should be children's interest as a starting point, not simply by teaching reference tissue, so that the teaching of picture books to become boring "routine." At the same time, teachers participate in the relevant training and teaching and research, not simply just go for the theory to be actively deeply internalized, to correct ideas into the correct behavior in the actual practice of teaching undertaken line these ideas will actually correct ideas and teaching activities combined. Of course, teachers should avoid the "rote" phenomenon, as some concept not suitable for all activities, not necessarily applicable to all teachers, teachers should be based on the actual situation of teaching these ideas to practice, so as to effectively conceptions your picture books teaching.

In addition to teachers speak or read review, teachers can also be based on the activity required in a timely manner of reading methods, such as interactive shared reading, allow a few of the same age or have a certain age differences of children to participate in reading, to increase opportunities for children to communicate, interactive excitation, may also be active thinking and atmosphere that makes teaching more interesting picture books. Secondly, teachers should adopt flexible multimedia 
technology, such as teachers in the use of multimedia technologies do not just behave according to the text of the original screen play-by-page order, but should be more cognitive difficulties Illustrated screen, prone to error or Multiple FIG expressing key issues used to preclude the use of multimedia technology assistance, such as the restructuring of the screen, sound configuration, the animation increases, the lens close-up, continuous page, etc., but also necessary, additions, deletions, or moving work part, without restrictions of time and space, making the entire teaching process is in a state of Smart, greatly increased the expression of picture books. Finally, teachers in the form of activity or activities may be appropriate to increase the process aspect of the performances, games, music, painting, dance and other methods, so that the form Events richer, more live call, more interesting.

\section{Conclusion}

Picture is the soul of picture books, picture books enjoy the process. Children understand the world through the screen, experience emotion, understand a wealth of knowledge and gradually establish their own life and values. In the process to enjoy picture books, children experience the artistic elements of picture books in the subtle method, such as color, composition, line, proportion, perspective, light and shadow relations, recognized from picture books in the world, understand art, appreciate the beauty, nourish the soul, strive to enrich the sense of art, all of those plays a good role in the children of artistic, aesthetic and emotional thinking ability cultivation.

\section{References}

[1] Prudhoe, C. M. Picture books and the art of collage. [J]. Childhood Education. 2003

[2] Stewig, J. W. Children's observations about the art in picture books. 1995

[3] Bowman, B, Committee on early childhood pedagogy. [J].Eager to learn educating our preschoolers. 2001

[4] Mitchell WJT. [J].Picture Theory. 1994

[5] Xu Qingli. Exploration Strategies handmade preschool teaching[J]. Chinese school education. 2016, (16) 